\section{Australian \\ Nursing and Midwifery \\ Conference}

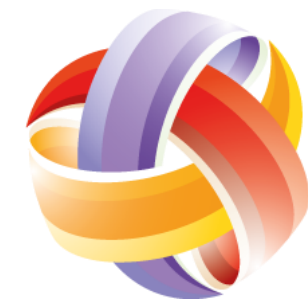

Aspiration, inspiration and imagination

nursing and midwifery quality, research and education

15th and 16th October 2015

Newcastle City Hall, Newcastle NSW

www.nursingmidwiferyconference.com.au

\title{
MIDWIFERY TRAINED REGISTERED NURSES' PERCEPTIONS ON THEIR OWN SERVICE: A QUALITATIVE STUDY IN SRI LANKA
}

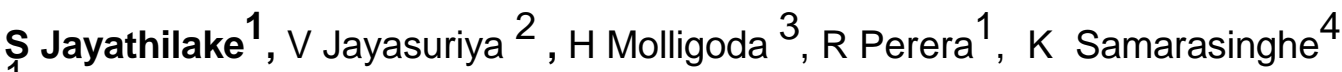 \\ ${ }_{2}^{1}$ University of Sri Jayewardenepura, Nugegoda, Colombo \\ 2 Ryerson University, Toronto, \\ 3 Post Graduate Institute of Medicine, Colombo, \\ 4 Kristianstad University, Kristianstad,
}

\section{Introduction}

The Midwifery Trained Registered Nurse (MTRN) is a part of the multi- disciplinary team of hospital based maternity care in Sri Lanka. MTRNs perform their duties by practice or tradition without clear job descriptions, thus exposing them to role conflicts within the team similar to other South Asian settings (Sharma, Johansson, Prakasamma, Mavalankar \& Christensson, 2013). The MTRN's scope of practice therefore needs to be carefully analysed in order to clarify their role, tasks and responsibilities. This study explores MTRN's perceptions of their own profession as maternity care providers.

\section{Method}

An exploratory qualitative study. Three focus group discussions (FGDs) were conducted with 22 MTRNs working in intra-natal or post-natal units in selected hospitals. FGDs were recorded, transcribed verbatim, and analyzed using qualitative manifest and latent content analysis.

\section{Results}

The overriding theme of the latent analysis was identified as 'competent but not allowed to blossom fully in their practice', based on two main categories: 'provision of competent care' and 'working with disappointments'. Each category had four subcategories: 'acting with compassion', 'cooperation in emergencies", 'exceeding one's boundaries', 'taking full responsibility'; and 'deprived of utilizing special knowledge and skills', 'role confusion with other professional groups', 'lack of professional identity' , 'not being appreciated by others' respectively.

\section{Conclusion}

In the Sri Lankan context, this is the first study that documents MTRNs' perception of their profession as maternity care providers. MTRNs' own profession of high proficiency is incongruent with their low sense of identity and belonging in the professional sphere. This phenomenon warrants further study considering its implications for MTRN's own role within the multidisciplinary team of the hospital based maternity care, and for patient safety.

\section{References}

Sharma, B., Johansson, E., Prakasamma, Mavalankar, D., \& Christensson, K. (2013). Midwifery scope of practice among staff nurses: A grounded theory study in Gujarat. India. Midwifery, 29, 628-636. 